\title{
Proceeding
}

8th INSHS International Christmas Sport Scientific Conference, 5-7 December 2013. International Network of Sport and Health

Science. Szombathely, Hungary

\section{Video analysis in youth volleyball team}

\author{
FABIO PARISI 14 , GAETANO RAIOLA ${ }^{2}$ \\ ${ }^{1}$ High Education Student SWARM - University of West-Hungary \\ ${ }^{2}$ Adjunct professor, University of Matera, Italy
}

\begin{abstract}
Parisi, F. \& Raiola, G. (2014). Video analysis in youth volleyball team. J. Hum. Sport Exerc., 9(Proc1), pp.S584-S587. The aim of the study was to use video analysis in training to improve the performance of young athletes. Participants will be divided in two teams that will play the same "Under-21 championship", but with a different average age (Team A: average age 14,41 $\pm 1,66$; Team $B$ average age 18,94 $\pm 1,59$ ). Twelve matches (in 4 months) of both teams will be videotaped. Statistical data for each team will be extrapolated from them, and compared among them in order to take in correlations skills data. Only team A, the "young team", will be given the opportunity to review errors and strong points of each match, so as to prepare for the successive match, according to the errors made in the matches. The videos will be analyzed by "Kinovea" software, while statistics analysed with "SoloStats 123 ". It is expected that there will be a performance improvement in young team A, around the same average level of "expert" team B. These results will be used as a starting point to analyze the differences between two teams with different average age, in a higher championship quality. Key words: VIDEO ANALYSIS, VOLLEYBALL, YOUTH TEAM.
\end{abstract}

Corresponding author. High Education Student SWARM - University of West-Hungary.

E-mail: parisifabio19@gmail.com

8th INSHS International Christmas Sport Scientific Conference, 5-7 December 2013. International Network of Sport and Health Science. Szombathely, Hungary.

JOURNAL OF HUMAN SPORT \& EXERCISE ISSN 1988-5202

(c) Faculty of Education. University of Alicante

doi:10.14198/jhse.2014.9.Proc1.50 


\section{INTRODUCTION}

The video analysis and Match Analysis are generally used by all Volleyball teams as an important component for the performance assessment in the match. The video analysis enables revision of the whole course of the match and a focus on the strengths and weaknesses of the team, both in tactics and technique. Instead, Match Analysis returns numerical data on the athletes' performance and the entire team. However, the video analysis is rarely used in training to teach the technique of motor execution or tactics used in the matches by youth athletes. This method takes time, and many people think, mistakenly, that it also requires large and expensive equipment, or deep knowledge of informatics. In a previous work done by our staff, it was shown that there are no difficulties in using this methodology in training, with youth teams.

In the literature, nothing exists about this field of study, just as there is nothing about the differences between teams of different average ages, but belonging to the amateur category. Therefore, the aim of this study is to analyze the differences between two teams of different age average (Team A: average age $14.41 \pm 1.66$; Team $B$ average age $18.94 \pm 1.59$ ) and use the video analysis in training, with only the team $A$, to attempt to improve the performance of young athletes. The goal is to bring the young team's performance, the performance of the Team B, composed equally by young athletes, but with more experience in volleyball.

Our study is based on the hypothesis that an expert team, although young, is constant in their performance, while a young team but inexpert, alternating high peak performance at times of very low performance, even within the same match. For this reason our aim is to stabilize the performance of the young team, using as a method of video analysis in training, to review with the athletes their errors and strengths, in order to prepare them to the next match, according to the errors committed in the match.

\section{METHODS}

Twenty six female athletes aged between 13 and 20 years will be analyzed for this study. The athletes are divided into two teams: Team A, experimental group ( $n=13$ athletes) and Team B, control group $(n=13$ athletes). Team $A$ is made up of athletes with an average age of $14.41 \pm 1.66$, inexpert, in their first participation in a League under $21 \mathrm{CIS}$ (Centro Sportivo Italiano). The Team B, however, is made up of athletes with an average age of $18.94 \pm 1.59$, in their second participation in the same league Under-21 CSI, having ranked 4th in Italy, in the National Finals held in the previous sporting year 2012/2013. Each team will be filmed at every match, and then we will carry out a statistical analysis of the match.

The instruments used are a simple camera to film the matches, Kinovea free software for video analysis, and SOLOSTATS123 for tablet, for statistical analysis. The camera is sufficient for the use that we're going to do, purely statistical, didactic, and for preparation at the race, in training, with Team A. Kinovea software can be downloaded free from the web, allows us to see the movie, save key images, draw on the video and slow down the images in order to understand strengths and weaknesses of the tactics and techniques of the team. The application SOLOSTATS 123 for tablet instead provides us with a simple and intuitive panel, where the events in the match can be entered, and automatically returns reports concerning all the fundamental skills (serve, spike, block, dig, receive), with detailed analysis for each athlete, set, the entire match and for rotation. 
Both teams participate in the same Under-21 Championship, lasting four months, from December 2013 to March 2014. The league consists of 12 matches for each team, making a total of 24 matches that will be analyzed. Usually matches are held on the weekend (Saturday or Sunday) and Monday will be a day dedicated to the vision of the match just carried out. Both teams will be shown the statistical reports of each match, but only to the Team $A$ is given the opportunity to review the match through the video: the coach along with the athletes will choose the points to work on in the next week of training in order that they do not make the same mistakes in the next match. Each team plays 3 training sessions per week ( 1 hour and 30 minutes for training), with the same coach. Thanks to SOLOSTATS123 we're going to retrieve statistics for: receive, spike, dig, serve, block, fouls. These are some of the software features:

- Player Management - Select only the player 6 starters plus the Libero to reduce the number of buttons on the screen. You can drag and drop your players in a special substitution screen to quickly modify your starters.

- Fast In-Rally buttons - Now just click the Dig, Hit in Play, Block in Play button next to the player to add that in-rally stat. No need to find the player then the action. This really speeds the in-rally action tracking. Just double tap the right in-rally button and the stat is logged.

- Match Stats - Use the Quick View feature to see aggregate match stats while you stat. Just swipe the Capture screen up to see the new stats. Summary stats are like box scores and show you all the important stats by player as well as how each rotation is doing.

- Point Tree - The point tree shows you how you got your total points as well as how your opponent got their points. The table shows Kills, Opponent Hitting Errors, Aces, Opponent Serving Errors, Blocks, Opponent Faults as well as Pass Ratings, Side Out \% and Point Scoring $\%$. Quickly understand how you are winning or losing a game.

\section{EXPECTED RESULTS \& DISCUSSION}

At the end of the season, having made all the statistical reports of the 24 matches, there will be a comparison between the two teams, and a detailed analysis of the time course of the statistics of only Team A. We expect that both teams achieve improvements during the course of the sporting year, but in particular we expect an improvement and a levelling performance of Team A, with the video footage of every match before the week of training.

\section{CONCLUSIONS}

The video analysis, as already experienced in previous studies (Raiola et al., 2013) is very useful in growth phase, and then in the youth teams to increase the learning of motor skills and technical in training. We expect a confirmation of this even in this last study. Also this study will be used as a starting point (pilot study) to develop the same study, revised through experience carried out with high-level teams but always with the same range of ages. Understanding the performance differences that exist between amateur teams, but of different average age, can help coaches to understand what to focus attention on in training and how to facilitate rapid learning of basic tactics and techniques that can be used by athletes for competition results. 


\section{REFERENCES}

1. Hughes, M. \& Franks, I. (2007). The Essentials of Performance Analysis: An Introduction. London: Routledge.

2. Ilics, K., Bakk, A., \& Suskovics, C. (2013). Researching the aptitude of young volleyball players (children and adolescents). J Hum Sport Exerc, 8(2), pp. S61-S71.

3. Nejić, D., Trajković, N., Stanković, R., Milanović, Z. \& Sporiš, G., (2013). A comparison of the jumping performance of female junior volleyball players in terms of their playing positions. Physical Education and Sport, 11(2), pp.157-164.

4. Raiola G. (2011). Bodily Communication in Volleyball between human and experimental sciences. Mediterranean Journal of Social Sciences, 3(1), pp.587-597.

5. Raiola, G. (2012). Didactics of volleyball into the educate program for coaches/trainers/technicians of Italian Federation of Volleyball (FIPAV). Physical Education and Sport, 12(1), pp.25-29.

6. Raiola, G., Parisi, F., Giugno, Y. \& Di Tore, P.A. (2013). Video analysis applied to volleyball didactics to improve sport skills. J Hum Sport Exerc, 8(2), pp.307-313. 